University of Nebraska - Lincoln

DigitalCommons@University of Nebraska - Lincoln

1995

\title{
Introduction to special section: Mechanical involvement of fluids in faulting
}

Stephen Hickman

U.S. Geological Survey

Richard Sibson

University of Otago

Ronald Bruhn

University of Utah

Follow this and additional works at: https://digitalcommons.unl.edu/usgsstaffpub

Part of the Earth Sciences Commons

Hickman, Stephen; Sibson, Richard; and Bruhn, Ronald, "Introduction to special section: Mechanical involvement of fluids in faulting" (1995). USGS Staff -- Published Research. 410.

https://digitalcommons.unl.edu/usgsstaffpub/410

This Article is brought to you for free and open access by the US Geological Survey at DigitalCommons@University of Nebraska - Lincoln. It has been accepted for inclusion in USGS Staff -- Published Research by an authorized administrator of DigitalCommons@University of Nebraska - Lincoln. 


\title{
Introduction to special section: Mechanical involvement of fluids in faulting
}

\author{
Stephen Hickman \\ U.S. Geological Survey, Menlo Park, California \\ Richard Sibson \\ Department of Geology, University of Otago, Dunedin, New Zealand \\ Ronald Bruhn \\ Department of Geology and Geophysics, University of Utah, Salt Lake City
}

\section{Introduction}

A growing body of evidence suggests that fluids are intimately linked to a variety of faulting processes. These include the longterm structural and compositional evolution of fault zones; fault creep; and the nucleation, propagation, arrest, and recurrence of earthquake ruptures. Besides the widely recognized physical role of fluid pressures in controlling the strength of crustal fault zones, it is also apparent that fluids can exert mechanical influence through a variety of chemical effects.

The United States Geological Survey sponsored a Conference on the Mechanical Effects of Fluids in Faulting under the auspices of the National Earthquake Hazards Reduction Program at Fish Camp, California, from June 6 to 10, 1993. The purpose of the conference was to draw together and to evaluate the disparate evidence for the involvement of fluids in faulting; to establish communication on the importance of fluids in the mechanics of faulting between the different disciplines concerned with fault zone processes; and to help define future critical investigations, experiments, and observational procedures for evaluating the role of fluids in faulting. This conference drew together a diverse group of 45 scientists, with expertise in electrical and magnetic methods, geochemistry, hydrology, ore deposits, rock mechanics, seismology, and structural geology. Some of the outstanding questions addressed at this workshop included the following:

1. What are fluid pressures at different levels within seismically active fault zones? Do they remain hydrostatic throughout the full depth extent of the seismogenic regime, or are they generally superhydrostatic at depths in excess of a few kilometers?

2. Are fluid pressures at depth within fault zones constant through an earthquake cycle, or are they time-dependent? What is the spatial variability in fluid pressures?

3. What is the role of crustal fluids in the overall process of stress accumulation, release, and transfer during the earthquake cycle? Through what mechanisms might fluid pressure act to control the processes of rupture nucleation, propagation, and arrest?

4. What is the chemical role of fluids in facilitating fault creep, including their role in aiding solid-state creep and brittle fracture processes and in facilitating solution-transport deformation mechanisms?

Copyright 1995 by the American Geophysical Union.

Paper number 95JB01 121.

0148-0227/95/95JB-01121\$02.00
5. What are the chemical effects of aqueous fluids on constitutive response, frictional stability, and long-term fault strength?

6. What are the compositions and physical properties of fault fluids at different crustal levels?

7. What are the mechanisms by which porosity and permeability are either created or destroyed in the middle to lower crust? What factors control the rates of these processes? How should these effects be incorporated into models of time-dependent fluid transport in fault zones?

8. What roles do faults play in distributing fluids in the crust and in altering pressure domains? In other words, when and by what mechanisms do faults aid in or inhibit fluid migration? What are the typical fluid/rock ratios, flow rates, and discharges for fault zones acting as fluid conduits?

9. Are fluids present in the subseismogenic crust, and by what transformation and/or transport processes are they incorporated into the shallower seismogenic portions of faults?

In spite of the enormous amount of field, laboratory, and theoretical work that has been directed toward the role of fluids in faulting over the past several decades, many of these questions remain unresolved due to the difficulty of either directly observing or inferring (with some degree of confidence) physical properties and deformation mechanisms along faults in the middle to lower crust.

Selected articles arising from this conference have been incorporated into this special section of the Journal of Geophysical Research; early versions of most of these papers appeared in the conference proceedings volume [Hickman et al., 1994]. To set the stage for these articles, in this Introduction we first present some of the key field evidence for the involvement of fluids in the mechanics of faulting and then discuss several of the recent conceptual models that have been developed for fluid flow and fluid-assisted deformation along fault zones. We then present brief synopses of the articles appearing in this special section and conclude with a summary of the key areas in which future research on the mechanical involvement of fluids in faulting is most urgently needed, based upon group discussions held at the conference.

\section{Evidence for the Involvement of Fluids in Faulting: A Historical Perspective}

Recognition of the role of faults as fluid conduits extends far back into mining history. While Von Oppel [1749] recognized 
that mineral veins occupied faults as well as fissure veins, Agricola [1556, p. 47] had earlier identified water as the causative agent in vein formation, stating that "...the force of the water crushes and splits the brittle rocks", thereby preempting modern understanding of hydraulic fracturing [Hubbert and Willis, 1957] by some four centuries! Buckland [1836, p. 548] subsequently noted that "...the greater part of metalliferous veins originated in enormous cracks and crevices penetrating irregularly and obliquely downward to enormous depth, and resembling the rents and chasms which are produced by modern earthquakes." It is scarcely surprising therefore that much of the structural terminology used for faults (e.g., hanging wall, footwall) derives directly from miner's parlance. Mining geologists had also noted that the textural characteristics of fault-hosted hydrothermal veins showed that the passage of hydrothermal fluids was generally episodic, and possibly coupled to incremental fault slip [e.g., Hulin, 1925; Knopf, 1929]. Interestingly, it was about this time that Mead [1925] published his classic paper calling attention to the geologic role of dilatancy. Newhouse [1942, p. 34] later commented that "...epigenetic ore deposits...appear rarely to have been introduced into dead or static structural features..." and went on to infer that "...evidence for repeated faulting or intermineralization fracturing is widespread..." during mineral deposition.

While McKinstry [1948] and other mining geologists had clearly achieved a qualitative appreciation of the role of fluid pressure in counteracting normal stress during faulting and vein formation, the seminal paper of Hubbert and Rubey [1959] stands out as the foundation work in structural geology applying Terzaghi's [1924] concept of effective stress in a quantitative manner to faulting in fluid-saturated rock. By recognizing the widespread development of fluids overpressured well above hydrostatic to near-lithostatic levels in sedimentary basins and applying the principle of effective stress, Hubbert and Rubey [1959] identified an important mechanism for lowering the strength of thrust faults, thereby reducing the basal frictional resistance to overthrust blocks. Recognition of overpressuring at depths of more than a few kilometers in sedimentary basins has since become widespread [Fertl et al., 1976], especially in basins undergoing active deformation, and the belief that much crustal deformation is focused in areas of fluid overpressure is now widely accepted in the structural geology literature [e.g., Fyfe et al., 1978]. A point to note is that there is good evidence that seismic rupturing, in at least some instances (e.g., the Western Taiwan fold and thrust belt and the western margin of the Great Valley adjacent to the San Andreas fault), is occurring in fluidoverpressured crust [Davis et al., 1983; Sibson, 1990].

The concept that high fluid pressures and the localization of deformation are linked has been reinforced by studies of active accretionary prisms in subduction complexes and their fossil equivalents. Accretionary prisms and foreland fold-and-thrust belts are the best documented examples of large-scale mountain systems where fluid pressure controls not only faulting but also the shape of the entire mountain belt [see Dahlen, 1990]. The low taper angles of many active prisms and fold-and-thrust belts, coupled with direct borehole measurements of fluid pressure in areas such as Taiwan, provide strong evidence for significant overpressuring within the prism and along the basal decollement [e.g., Davis et al., 1983]. Additional evidence for superhydrostatic fluid pressures is gleaned from natural exposures of uplifted prism rocks, which contain vein networks filled with calcite, zeolite, quartz, and other hydrothermal precipitates thereby suggesting that fluid pressures frequently exceeded the least principal stress down to depths of $45 \mathrm{~km}$ [e.g., Platt, 1986; Moore and Vrolijik, 1992]. The existence of weak intraplate thrust faults beneath accretionary prisms and at greater depths within subduction zones, perhaps indicative of elevated fluid pressures alom these faults, is also supported by observations of near-surface hex flow, earthquake focal mechanisms in the adjacent crust, spatiol variations in the orientation of folds and faults in upper plate rocks, and metamorphic mineral assemblages in exhumed forearc terranes [van den Beukel and Wortel, 1988; Byrne and Fisher, 1990; Barr and Dahlen, 1990; Magee and Zoback, 1993].

An exciting recent development has been the revelation from careful borehole measurements of abrupt transitions, both vertically and laterally, between distinct fluid pressure regimes in some sedimentary basins. These "fluid pressure compartments" are bounded by seals which in some cases are stratigraphic (e.g., shale horizons) but in others are gouge-rich faults or thin zones of hydrothermal cementation which cut across stratigraphy [Hunt, 1990; Powley, 1990].

Important issues are whether fluid overpressures are common in other than compressional thrust regimes (overpressures in shale-rich sediments along the Gulf Coast of North America demonstrate that this may also happen in normal faulting regimes) and in crystalline basement rocks as well as in the sedimentary cover. Widespread development of "crack seal" extensional veins inferred to have developed by hydraulic fracturing in rocks deforming under greenschist and greater metamorphic grades [Ramsay, 1980; Etheridge et al., 1984] suggests that fluid overpressures may occur over broad regions during prograde metamorphism, and the association of arrays of extensional hydrofractures with mesothermal gold-quartz vein systems hosted in shear zones within crystalline basement points to the role of the shear zones as conduits for focused flow of overpressured fluids [Kerrich and Allison, 1978; Robert et al., 1983; Cox et al. , 1986].

The possibility of active crustal-penetrating faults acting as conduits for high-pressure mantle-derived fluids has been raised by a number of workers, but definitive evidence remains elusive [see discussion by Rice, 1992]. Irwin and Barnes [1980] noted the worldwide association of $\mathrm{CO}_{2}$-rich springs with seismic belts, inferring a possible mantle source. Elevated ${ }^{3} \mathrm{He} /{ }^{4} \mathrm{He}$ ratios, attributed to a mantle gas component, have been correlated with areas of extensional tectonic activity in westem Europe [Oxburgh and O'Nions, 1987] and with areas of earthquake swarm activity in Japan [Wakita et al., 1987]. More recently, Giggenbach et al. [1993] have reported elevated ${ }^{3} \mathrm{He}^{4}{ }^{4} \mathrm{He}$ ratios in seismically active areas of compressional tectonics in New Zealand, as well as in volcanically active regions in extensional tectonic regimes.

Direct evidence of the effect of fluid pressure on fault stability has come from earthquakes induced in intraplate regions either through direct injection of fluids down boreholes, as at Denver and Rangely in Colorado [Healy et al., 1968; Raleigh et al., 1976] and in Cornwall in SW England [Pine and Batchelor, 1984], or from the filling of large reservoirs with subsequent infiltration of water into the underlying rock mass (distinct from the direct loading effect of the reservoir water mass) [Simpson, 1986]. In the few cases where sufficient information has been available on the state of stress, fluid pressure levels, and rock strength/friction parameters, the induced seismicity has provided good confirmation of the applicability of the principle of effective stress coupled to the Coulomb failure criterion in at least the top few kilometers of the crust [Raleigh et al., 1976; Zoback and Hickman, 1982; Zoback and Healy, 1984; Nicholson and Wesson, 1990].

Additional evidence for fluid involvement in faulting also comes from the substantial changes in both groundwater level and surface discharge $\left(10^{7}-10^{9} \mathrm{~m}^{3}\right)$ that have been observed to follow 
some earthquakes in the shallow crust. However, simple interpretations of these discharges as resulting from the rupturing of permeability barriers along faults (e.g., as predicted by the fault valve model of Sibson [1981]) do not seem to work in most cases, as the observed upwellings are typically not localized to the fault zones [see Muir-Wood and King, 1993]. There is also considerable debate on the sources of the discharging fluids: whether they originate from depths of the order of several kilometers due to coseismic strain changes in the surrounding crust [e.g., MuirWood and King, 1993] or are largely the result of near-surface changes in fracture permeability induced by strong ground motion [Rojstaczer and Wolf, 1992; Hickman and Rojstaczer, 1994].

\section{Recent Conceptual Models}

Interest in the role of fluids in faulting has been rekindled in recent years by measurements of heat flow and stress orientations indicating that the San Andreas fault, and perhaps other major plate boundary faults as well, is anomalously weak with respect to much of the Earth's crust (see review by Hickman [1991]). A number of theories have been proposed to explain the weakness of the San Andreas fault, most of which call upon superhydrostatic fluid pressures or the presence of chemically reactive fluids within the fault zone. Although it is often proposed that the presence of clays along faults might lead to anomalously low friction, tests on natural clay-rich fault gouges collected from the San Andreas at depths of less than $0.4 \mathrm{~km}$ [Morrow et al., 1982] and on synthetic clay-rich fault gouges [Logan and Rauenzahn, 1987; Marone et al., 1990; Morrow et al, 1992] indicate coefficients of friction at hydrostatic fluid pressures and realistic in-situ confining pressures that are too high to be reconciled with either the heat flow or stress orientation data [e.g., Lachenbruch and Sass, 1980; Zoback et al., 1987].

Both Rice [1992] and Byerlee [1990] have proposed that largescale yielding could lead to a rotation and an increase in the magnitudes of the principal stresses within the fault zone relative to their values immediately outside of the fault. If so, this would allow the fluid pressure within the fault zone to exceed significantly the magnitude of the least principal stress in the country rock. In this manner, permanently high pore pressures within an intrinsically strong (i.e., high coefficient of friction) San Andreas fault zone, in conjunction with near-hydrostatic fluid pressures in the surrounding rock, might lower the fault strength sufficiently to satisfy both the heat flow and stress orientation constraints. The high fluid pressures within the fault required by these models might be generated and maintained by continued upwelling of overpressured fluids within the fault zone and leakage of these fluids into the country rock [Rice, 1992]. Alternatively, high fluid pressures might result from the sealing of locally derived highpressure fluids within the fault zone once pressure gradients drop below a critical "threshold" required to overcome forces between molecular water and mineral surfaces in very small cracks and pores [Byerlee, 1990].

Solution transport deformation mechanisms such as pressure solution, fluid-assisted mineral reactions, and crack healing may be quite important in determining the rheology of fault zones [e.g., Rutter and Mainprice, 1979; Sibson, 1983; Blanpied et al., 1992] and the timescales of interseismic strength recovery [e.g., Angevine et al., 1982; Chester and Logan, 1986]. The establishment of impermeable barriers along fault zones through fracture healing and sealing, followed by episodic fracturing and permeability enhancement during earthquakes, has been proposed as one mechanism whereby fluid pressures might be intermittently high and intimately linked to the earthquake cycle [e.g., Sibson, 1992; Sleep and Blanpied, 1992; Byerlee, 1993].

Alternative models which might explain the low long-term strength of the San Andreas, at least along seismically active segments of the fault, have called upon processes directly associated with earthquake rupture propagation. These dynamic weakening mechanisms include shear heating during slip, leading to transiently high fluid pressures (see below), and reductions in normal stress accompanying the propagation of dilational waves along the fault [Brune, 1993].

\section{Sources of Fluids in Faults and Shear Zones}

Potential sources of fluids in brittle faults and shear zones include metamorphic fluid generated by dehydration of minerals during prograde metamorphism (including shear heating), fluid trapped in pore space as sedimentary formation brines, and meteoric water carried downward by circulation [Kerrich et al., 1984]. Fluid exsolved from magma is another potential source, at least in certain thermal regimes, and, as discussed above, there is isotopic and geochemical evidence that mantle-derived water and carbon dioxide may be upwelling along some major crustalpenetrating faults.

Fluids in the forearc regions of subduction zones can originate from a variety of sources. Consolidation of underthrust sediments appears to provide most of the fluid in the upper several kilometers of accretionary prisms [Bekins and Dreiss, 1992]. Other sources of fluid that become increasingly important at greater depths along subduction zones are mineral dehydration reactions, including the smectite-to-illite transition and the dehydration of zeolites and other hydrous minerals in altered seafloor basalt. Maturation of organic matter may also play a major role in controlling fluid pressure through the generation of both liquid and gaseous hydrocarbons [Moore and Vrolijk, 1992].

Geological, geochemical, and isotopic studies of fault-hosted hydrothermal minerals provide important constraints on the origin of fluids. Kerrich et al. [1984] studied hydrothermal minerals in several fault and shear zones and suggested a general sequence of flow regimes that evolves during shear zone evolution. Initial alteration in deep-seated shear zones is characterized by locally derived fluids and low water/rock ratios, presumably due to restricted permeability during the early stages of shear localization. Subsequent alteration occurs under higher fluid fluxes, with contributions from both metamorphic and connate fluids as the shear zone grows and intersects more distant crustal reservoirs. This flow regime is characterized by high water/rock ratios and chemically reduced fluid. Incursion of oxidizing fluids derived from near-surface reservoirs is often observed at higher crustal levels, in the regime dominated by brittle deformation.

The composition of fault zone fluids varies widely, depending on the source for the fluid, the amount of water-rock interaction along the flow path, and the direction and amount of fault offset [Parry, 1994]. For example, deep seated crystalline rocks in the hanging wall of reverse faults may move upward, over the top of sedimentary sequences, allowing formation brines to percolate into the hanging wall. Alternatively, subsidence of the hanging wall in normal faulting regimes may mix near-surface-derived fluids with metamorphic fluids expelled from the deeply seated footwall. Lateral displacement along large strike-slip faults can juxtapose rock units of markedly different lithologies and fluid compositions, leading to spatial and temporal variations in fluid chemistry within the fault zone [e.g., Evans and Chester, this issue]. 
Large fluxes of deep-seated fluid are required for the deposition of veins and associated hydrothermal alteration in many shear zones and fault systems [e.g., Cox et al., 1986; Boullier and Robert, 1992]. This observation is consistent with some of the more recent models that have been proposed for the hydromechanical behavior of fault zones, such as the fault valve model [Sibson, 1981; 1992; Sibson et al., 1988] and Rice's [1992] steady state permeability model. The fault valve model requires a large volume of high-pressure fluid to accumulate beneath a lowpermeability seal at the base of a fault zone during the interseismic period; this seal is then ruptured and the fluid surges upward immediately following the earthquake. In contrast, Rice's model requires the continual upwelling of overpressured fluid from the ductile root of a fault zone and does not consider possible variations in fluid pressure during the seismic cycle In other faulting environments, however, there is some indication that mass transfer is a more localized process, with crack-sealing minerals and vein deposits derived from nearby sources through pressure solution and other diffusive-mass-transfer processes [Gratier et al., 1994].

\section{Permeability Structure and Flow Paths}

The permeability structure of shear zones and brittle faults has recently been the focus of field studies that both confirm and extend observations made years ago by mining geologists [e.g., Knopf, 1929; McKinstry, 1948; Guilbert and Park, 1985]. Large faults are not discrete surfaces but rather are a braided array of slip surfaces encased in a highly fractured and often hydrothermally altered transition or "damage" zone [Smith et al., 1990; Bruhn et al., 1990, 1994; Chester et al., 1993]. Structural and mineralogical textures indicate that episodic fracturing and brecciation are followed by cementation and crack healing, leading to cycles of permeability enhancement and reduction along faults.

A number of recent experimental studies carried out at hydrothermal conditions allow one to estimate the time required for processes such as crack healing and sealing and hydrothermal alteration to significantly alter fault zone permeability. In most cases, these processes operate at rates that are rapid with respect to the 100- to 10,000 -year recurrence intervals for large earthquakes [e.g., Brantley et al , 1990; Blanpied et al., 1992; Moore et al., 1994]. Recognition of the high rates at which these solution transport processes operate is perhaps one of the most important conceptual breakthroughs in understanding the hydromechanical behavior of fault zones during the last decade. In shearing experiments on granite gouge sandwiched between granite forcing blocks, Blanpied et al. [1992] showed that redistribution of material in solution can quickly reduce the granite permeability, causing a self-generated impermeable seal which isolates the deforming fault from the nearby country rock. Compaction of the fault gouge before and during shear then causes fluid pressure in the fault zone to rise, allowing slip at low shear stress. Subsequent theoretical modeling [Sleep and Blanpied, 1992, 1994] showed that the generation of dilatant pores and microcracks during earthquakes in a hydraulically isolated fault zone, followed by creep compaction between earthquakes, might lead to cyclically high fluid pressures along faults.

Geothermal fields provide an active hydrothermal environment where permeability destruction by crack healing and mineral precipitation competes with, and may overwhelm, permeability creation by distributed faulting and fracturing [Batzle and Simmons, 1977]. Permeability destruction in some fields is, in fact, sufficiently fast for them to generate and maintain their own cap rocks through this process of hydrothermal self-sealing [Facca and Tonani, 1967]. In the Wairakei and Broadland fields in the North Island of New Zealand, high-permeability faut breccia zones for steam production are found only along the most recently reactivated structures, older faults having become choked with hydrothermal precipitates (quartz, calcite, zeolites, adularis, etc.)[Grindley and Browne, 1976]. Though precipitation is extremely rapid in the near-surface hydrostatic boiling regime (as evidenced by the gold-plating of pressure reduction valves Broadlands [Brown, 1986]), these geothermal systems provide important analogs to the competing processes of permeability creation and destruction likely to operate at significant depth in major crustal fault zones, especially in the region toward the base of the seismogenic zone. The analogy may be extended still further if there is a transition from approximately hydrostatic pressures in the near-surface to near-lithostatically pressured fluids at the base of some geothermal fields, as Fournier [1991] has suggested.

Fault-hosted fracture arrays differ markedly between reverse, normal, and strike-slip faulting regimes, with important implica tions for the development of rock permeability and fluid conduits. Fault displacement is concentrated on undulating surfaces which generate and destroy void space during slip as the result of mismatched surface topography [Newhouse, 1940]. The void space, which is partly filled with breccia, cataclasite, and gouge, is elongated parallel to the slip direction and provides tortuous conduits that channel fluid flow [Newhouse, 1940; Bruhn et al., 1994]. Fracture arrays in the damaged rock surrounding the primary slip zone provide local reservoirs for fluid accumulation and expulsion but become partly sealed over time by hydrothermal processes. Reverse faults may be characterized by subhorizontal veins which extend into the country rock on either side of the main fault zone [e.g., Robert et al., 1983; Cox et al., 1986]. When they are areally extensive, these veins are thought to develop by episodic influx of fluid at pressure equal to or even slightly in excess of the overburden pressure [Sibson, 1992]. Normal and strike slip faults may be characterized by steeply dipping extension fractures, which develop either as small-scale "wing" cracks emanating off of moderately dipping to vertical shear fractures or as more extensive arrays of tensile fractures [Tchalenko, 1970; Bruhn et al., 1994].

By analogy with the fluid pressure compartments observed in some sedimentary basins, Byerlee [1993] proposed a model in which contiguous vertical and horizontal seals within a fault zone would lead to discrete fluid pressure compartments (i.e., tabular lenses), the rupture of which might be important in earthquake nucleation and propagation. Although direct evidence for these fault zone fluid compartments is lacking, negative polarity reflections (bright spots) on seismic reflection images acquired over some accretionary prisms have been interpreted to indicate the existence of high-pressure fluid compartments along the basal decollements [Moore and Vrolijk, 1992; Shipley et al., 1994].

\section{Transient Fluid Pressure Effects}

For the most part, the Hubbert and Rubey [1959] analysis and those that followed it in the structural geology literature were quasi-static, taking no account of the mode of fault slip or of the variations in permeability and fluid pressure that might arise from faulting. This quasi-static, high fluid pressure approach to faulting contrasts with the dilatancy/fluid diffusion hypothesis for shallow crustal earthquakes evolved by the seismology/rock 
mechanics community [e.g., Nur, 1972; Scholz et al., 1973], where massive fluid redistribution at close to ambient hydrostatic fhuid pressures was inferred to occur in response to the earthquake cycle of shear stress accumulation and release. While belief in extensive microcrack dilatancy formed under high differential stress levels as an earthquake precursor has waned, it is almost inevitable that some form of stress-dependent dilatancy is associated with active faulting, though significant dilatant strains may be restricted to the immediate vicinity of fault zones [Sibson, 1994].

A range of physical effects arising from the mechanical response of fluid-saturated crust has been invoked to account for time-dependent phenomena associated with faulting such as slow earthquakes, creep events, afterslip, and aftershock activity and its decay [e.g., Nur and Booker, 1972; Rice and Cleary, 1976]. Transient changes in fluid pressure and effective stress have also been suggested to play a direct role in rupture propagation and arrest. Shear resistance on the rupture surface may be dramatically lowered by localized increases in fluid pressure from frictional heating or locally elevated as a consequence of pore fluid diffusion and dilatant hardening at fault jogs and other irregularities [Sibson, 1973, 1985; Lachenbruch, 1980; Mase and Snith, 1987; Rudnicki, 1988]. Our understanding of the importance of these various processes in the Earth has, however, been hampered by our lack of detailed knowledge of the appropriate hydraulic parameters (especially the permeability structure) in and around active fault zones. The issue is further complicated by the possibility of chemical water-weakening effects such as stress corrosion, which could by themselves account for many of the longer-term time-dependent effects [Das and Scholz, 1981].

\section{Chemical Effects of Fluids on Fault Zone Rheology}

Over the past several years a number of fault mechanics models have either been developed or refined that incorporate competing, solution transport deformation mechanisms that at times weaken and/or destabilize the fault zone and at other times act to cement the fault zone together, thereby increasing fault strength. The experimental and theoretical studies on which these models are based are now focusing on processes that have long been inferred as being important from field observations of natural fault and shear zones, such as pressure solution, fluid-assisted retrograde mineral reactions, crack healing, and cementation [e.g., Kerrich et al., 1984; Power and Tullis, 1989; Bruhn et al, 1990; Boullier and Robert, 1992; Chester et al., 1993]. These deformation mechanisms are all interrelated, in that they depend upon thermally activated chemical reactions between the rock and pore fluid as well as the rates at which dissolved species are transported through the pore fluid.

Laboratory and theoretical investigations have shown that pressure solution may be important in reducing long-term fault strength and in promoting aseismic slip (i.e., creep) along faults [e.g., Rutter and Mainprice, 1979; Tada et al., 1987; Chester and Higgs, 1992]. This is especially likely in the middle to lower crust where high confining pressures and low-to-moderate temperatures inhibit both frictional sliding and crystal-plastic deformation, respectively [e.g., Kirby, 1980; Sibson, 1983]. In contrast, in addition to allowing the formation of pressure seals, solution transport processes such as crack healing and sealing and cementation may cause the welding together of asperities or fault gouge, leading to time-dependent fault strengthening between earthquakes [e.g., Angevine et al., 1982; Hickman and Evans, 1992; Fredrich and Evans, 1992]. Laboratory friction experi- ments conducted under hydrothermal conditions suggest that a change in dominant deformation mechanism with increasing depth from brittle deformation to solution transport creep might control the depth at which the seismic-to-aseismic transition occurs in the crust [Blanpied et al., 1991]. Ultra-fine-grained fault gouge and cataclasites should be particularly reactive in the presence of aqueous pore fluids, allowing solution transport fault creep to proceed under relatively low resolved shear stresses [e.g., Chester and Higgs, 1992].

Hydrothermal mineral reactions can also weaken crustal rocks when the reaction products are weaker than the reactants [e.g., Janecke and Evans, 1988; Shea and Kronenberg, 1993]. Janecke and Evans [1988] showed that muscovite formed from the breakdown of feldspar in granite dramatically lowered the ductile shear strength of the granite (presumably due to basal plane dislocation glide in the micas), even at temperatures well below those necessary for the plastic flow of quartz. At least at shallow depths, fault zones such as the San Andreas are mostly composed of clay- and mica-rich gouge resulting from the hydrolysis of feldspar [e.g., Wu, 1978], suggesting an enhancement of the feldspar breakdown reaction within the fault zone. Stressenhanced hydrothermal mineral reactions are also recognized to be important in weakening crustal rocks, even when both the reactant and product phases are strong [e.g., Rubie, 1983]. For example, reactions in the olivine-talc-serpentine-water system have been demonstrated to dramatically lower the shear strength of ultramafic rocks in laboratory friction experiments [Pinkston et al., 1987].

\section{Synopses of Papers}

The papers by Cox and by Robert, Boullier, and Firdaous provide evidence from fault-hosted hydrothermal vein systems (mesothermal gold-quartz lodes) for faulting under nearlithostatic fluid pressure conditions in the lower regions of the continental seismogenic zone. Development of such major goldquartz assemblages requires throughput of substantial fluid volumes and cannot be accounted for by local fluid redistribution. The vein systems are inferred to have developed through extreme fault valve action on steep reverse faults, with episodic postseismic flushing of deep crustal fluids through the fault zones accompanied by large-amplitude fluid pressure cycling. Important facets of these studies are the recognition from the vein structures of evidence for total stress relief accompanying increments of fault slip and the semiquantitative estimates of both the fluid volume discharged per slip increment (Cox) and the magnitude of the fluid pressure drop accompanying discharge (Robert et al.). Cox focuses on a single vein system in the Paleozoic Victorian gold field, Australia, while Robert et al. discuss the extensive late Archean vein field occupying secondand third-order structures in the Val d'Or mining district, Quebec, and speculate on its possible relationship to either foreshock or aftershock activity accompanying large rupture events on the adjoining Larder Lake-Cadillac Break, a crustal-scale fault structure.

Three papers in this issue deal with fault strength and fluid pressures in the forearc regions of subduction zones. Fisher, Brantley, Everett, and Wambold discuss evidence for cyclic fluid flow deep in the interior of accretionary prisms, through an analysis of pervasive crack seal vein systems within the accretionary prism exposed on Afognak Island, Alaska. These nearvertical, en echelon vein arrays form part of the plumbing system for fluid transport within a sequence of sedimentary rocks that 
were underplated near the base of the accretionary wedge at depths of 8 to $12 \mathrm{~km}$. Vein textures and rock chemistry indicate that the veins episodically dilated and collapsed during the history of fluid influx and outflow, suggestive of an interconnected fracture network that grew either quasi-statically or suddenly during earthquakes. They propose a novel "zipper model" for quasi-static vein formations, in which lenses of fluid less than a meter in length move upward through the veins as silica diffuses from the wall rock to the base of the vein, where quartz is precipitated to seal the fracture shut.

Moore, Moore, and Cochrane present new geophysical evidence for overpressured fluid compartments in faults associated with the Oregon accretionary prism through an analysis of multichannel seismic reflection data. High amplitude reversedpolarity reflections were seen both along the main frontal thrust zone and along more distributed smaller-scale protothrusts seaward of the prism. The reversed-polarity zones along the frontal thrust occur as discrete bands extending about $3 \mathrm{~km}$ parallel to the strike of the fault and about $1 \mathrm{~km}$ downdip; similar but smaller zones occur along the protothrusts. Of the two possible explanations considered for these reversed-polarity reflections, overpressured fault-zone fluid compartments and the thrusting of higher- over lower-impedance sediments, analysis of fault displacements and stratigraphically controlled variations in velocity/density structure across the faults shows that overpressured fluid compartments are the most likely. Modeling of the seismic waveforms suggests that the overpressured compartments, or lenses, inferred within the major frontal thrust zone are about $10 \mathrm{~m}$ thick.

From the low surface heat flow in the forearc of the northern Cascadia subduction zone and the character of focal mechanisms which indicate strike-parallel compression along the margin, Wang, Mulder, Rogers, and Hyndman constrain the average shear strength of the main subduction interface to be less than $20 \mathrm{MPa}$ (i.e., comparable to the inferred shear resistance of the San Andreas fault at depths of 0-14 km [Lachenbruch and Sass, 1980]). They propose that high fluid pressure along the contact is one poten tial mechanism for maintaining this low shear strength. If so, then it is interesting to speculate that these fluids might have been incorporated into the main subduction interface in the form of overpressured compartments like those interpreted to exist at shallower depths by Moore et al. (this issue) along the nearby Oregon margin.

Citing numerous case studies, Eberhart-Phillips, Stanley, Rodriguez, and Lutter present a thorough review of surface-based seismic and electrical methods that have proven useful in imaging fault zones and discuss their strengths and limitations in inferring porosity, fluid pressure, and fault zone geometry at depth. Using synthetic seismic and magnetotelluric images of fault zones, they also test the resolution of these techniques for fault zone velocity and electrical conductivity structures under idealized conditions. For a simple fault geometry, these simulations indicate that it should be possible to image even a thin $(-0.5 \mathrm{~km})$ fault zone with a $20 \%$ reduction in $P$-wave velocities at $9 \mathrm{~km}$ depth using tomographic ray-tracing techniques if numerous earthquakes are available as sources within the fault zone. Similarly, magnetotelluric methods are shown to be capable of imaging conductive fault zone cores of the order of $1 \mathrm{~km}$ in thickness down to a depth of about $10 \mathrm{~km}$.

Two papers present geophysical evidence for the breaching of fluid pressure compartments along the San Andreas fault system during earthquakes. Johnson and McEvilly present an analysis of the clustering and migration of microearthquake activity along the transition from creeping to locked segments of the San Andreas fault at Parkfield, California. The activity occurs within and neer the edges of a tabular zone of low velocity, anisotropic material with a high $V_{P} / V_{S}$ ratio inferred to represent a dilatant, and possibly overpressured, fault zone. The expansion of these earthquake clusters with time is consistent with the migration of overpressured fluids from breached compartments. Fenoglio, Johnston, and Byerlee explore the electromagnetic consequences of rupture and fluid flow along the fault zone. Their analysis shows that the fields generated could explain the precursory anomalous ultra-low-frequency electromagnetic emissions that were observed in the epicentral region of the $1989 M=7.1$ Loma Prieta earthquake in California. They conclude that electrokinetic effects accompanying the rupturing of overpressured fluid compartments with impermeable seals provide the most plausible mechanism for these emissions.

As a means of characterizing fault zone heterogeneity using earthquake statistics, Ben-Zion and Rice conduct numerical simulations of slip instabilities on a vertical strike-slip fault using a variety of assumptions about the nature and scale of this heterogeneity. These heterogeneities include geometrical irregularities, variations in intrinsic frictional response, and a variety of nonhydrostatic fluid pressure distributions. By comparing the frequency-size distributions of earthquakes predicted by these simulations with seismological observations, they conclude that gradual pore pressure variations along faults, in and of themselves, cannot explain the spatial and temporal complexity exhibited by seismic slip. Rather, they propose that either strong fluid pressure compartmentalization, geometric disorder, or variations in intrinsic frictional properties within fauk zones are required to generate realistic earthquake statistics.

The 1992 Landers, California, earthquake $(M=7.2)$ triggered an abrupt increase in seismicity over much of the western United States. Hill, Johnston, Langbein, and Bilham present a detailed analysis of this triggered response at the Long Valley caldera, located about $400 \mathrm{~km}$ from the epicenter, using a unique data set consisting of local recordings of earthquake locations, tilt, volumetric strain, and geodetic line length changes. This response consisted of a surge in seismicity and a transient strain pulse that initiated immediately after passage of the Landers $S$ wave and then exponentially decayed over a period of several days. Mechanisms proposed to explain this response include a surge in fluid pressure within the seismogenic crust due to the cascading rupture of superhydrostatic fluid pressure compartments and the transient pressurization of shallow magma bodies by advective overpressure. However, Hill et al. prefer models calling upon the triggered shear relaxation of a partially crystallized magma body or dike intrusion into the lower crust, as these models are able to satisfy all of the observations with a single deformation source. This raises the intriguing possibility that large earthquakes can trigger the episodic recharge of the deep roots of crustal magma systems over a very large area.

Evans and Chester report on the effects of mechanical mixing and fluid alteration in the San Gabriel fault zone, an exhumed part of the San Andreas fault system. The protolith was strongly deformed and locally altered during faulting to form a narrow, well-defined fault core consisting of ultra-cataclasite sandwiched between a layer of foliated cataclasite. They cite evidence for heterogeneous fluid flow and alteration in the fault zone. In some areas, rocks in the fault core were deformed. and altered in a closed fluid system, where wall rock material was mixed and altered without extensive in- or out-flux of chemical species. At other localities, however, the chemistry of fault core rocks 
requires considerable volume loss, which implies significant fluid flow and chemical transport of mobile species, particularly silica. They emphasize that such heterogeneity may have important implications for spatial and temporal variations in the mechanical behavior of the fault.

In a related study, Wintsch, Christofferson, and Kronenberg discuss the geochemical conditions under which hydrothermal Iteration reactions might lead to the chemical weakening of fault zones (reaction softening), as strong feldspars are replaced by weak phyllosilicates. They suggest that a hydrated phyllosilicaterich fault rock slipping predominantly by dislocation glide may develop a low and pressure-independent shear strength, approaching that of mica single crystals ( $<10 \mathrm{MPa}$ ), without fluid overpressuring if the phyllosilicate grains are preferentially oriented and highly contiguous. They speculate that reaction softening promoted by the presence of $\mathrm{Mg}$-rich wall rocks, in particular, might explain the low long-term strength of the creeping segment of the San Andreas fault in central California.

The papers by Chester and by Blanpied, Lockner, and Byerlee use results from laboratory friction experiments at elevated temperatures and in the presence of water to make predictions about fault strength and the stability of sliding along wet crustalpenetrating faults. Chester uses a multimechanism state variable friction law previously derived from laboratory experiments on fine-grained quartz gouge [Chester and Higgs, 1992; Chester, 1994] to modify the traditional two-mechanism rheologic law for the crust (i.e., based on Byerlee friction and power law creep). This new rheologic model incorporates three distinct deformation mechanism fields in the frictional regime controlled, to varying degrees, by cataclasis and solution transport deformation. As Chester's model is cast in terms of shear strain rate, increasing the thickness of the fault zone at constant displacement rate is predicted to decrease fault strength and promote stable sliding. Application of this model to strike-slip faults indicates that their frictional strength should be significantly reduced (i.e., to the extent expected for a weak San Andreas fault) only for very thick fault zones or faults partially weakened by superhydrostatic fluid pressures. However, at geological slip rates, this model predicts that only very thin faults will display the rate-weakening behavior generally assumed necessary for frictional instabilities and the nucleation of earthquakes.

Blanpied, Lockner, and Byerlee performed a similar suite of experiments on fine-grained granite gouge. Samples deformed at low temperatures exhibited coefficients of friction in accord with Byerlee's law, whereas samples deformed above $400^{\circ} \mathrm{C}$ were significantly weaker than dry samples deformed at the same temperatures. As in the Chester study, Blanpied et al. infer that solution transport processes combined with cataclasis dominate deformation in these wet, high-temperature experiments. By fitting their data to Chester and Higg's [1992] multimechanism constitutive law, but recast in terms of sliding velocity as opposed to strain rate (as appropriate to their granite experiments), Blanpied et al. use their data to predict strength as a function of depth along strike-slip faults. This analysis suggests that at depths greater than about $9 \mathrm{~km}$, the strength of faults sliding at geologic rates may be considerably reduced below values expected from low-temperature friction experiments. As in the Chester model, however, superhydrostatic fluid pressures must also be invoked to explain the apparent weakness of the San Andreas fault. Blanpied et al. and Chester both note that additional solution-transport weakening of faults might result from factors not considered in their studies, including variations in mineralogy and pore fluid chemistry.
The preceding two papers treat fluid pressures along faults as time-invariant. In contrast, the paper by Sleep extends earlier models by Sleep and Blanpied [1992, 1994] for the cyclic generation of superhydrostatic fluid pressures along faults due to time-dependent compaction to incorporate rate- and state-variable friction. This formalism is able to predict a wide range of faulting behaviors, including repeating earthquake cycles and stable sliding, as well as the transitions between these two modes of behavior. Although earthquakes are produced in these simulations, even small amounts of dilatancy during the onset of slip are predicted to decrease fluid pressure sufficiently that unstable sliding is prevented (i.e., through dilatant hardening). To circumvent this problem, Sleep proposes either that thermal pressurization of pore fluids during slip may be sufficient to offset the predicted pore pressure decrease or that the dilatant pores created during sliding are sufficiently isolated from the sliding surface that the effects of this dilatancy on fluid pressure along the sliding surface is not immediately realized.

The papers by Lockner and Evans and by Dewers and Hajash describe laboratory studies of the time-dependent densification of quartz powders in the presence of water at elevated temperatures. These studies are important for understanding processes that could contribute both to permeability reduction in a porous fault gouge and to the generation of excess fluid pressures within fault zones through creep compaction (e.g., Sleep, this issue). Lockner and Evans measured the rate-of-change of porosity and electrical conductivity in ultrafine quartz powders compacted wet at high temperature $\left(700^{\circ} \mathrm{C}\right)$ and moderate effective confining pressures $(170-340 \mathrm{MPa})$. Porosity and electrical conductivity decreased monotonically during these experiments, with the most rapid changes occurring at high porosities (i.e., small elapsed times). These data are consistent with a model in which a decrease in conductivity results from a loss of total pore volume in the initial stages of compaction but is controlled by the uniform shrinkage of constrictions, or fluid channels, between pores after compaction reduces porosity to below $15 \%$. This model predicts that under certain conditions pores in a compacting fault gouge could remain interconnected, and thus capable of conducting either electrical current or fluid, down to very small porosities.

Dewers and Hajash measured volumetric strain and changes in pore-fluid silica concentration during compaction of a naturally rounded quartz sand at low temperatures $\left(150-200^{\circ} \mathrm{C}\right)$ and low effective confining pressures $(<50 \mathrm{MPa})$. Compaction rates increased with increasing effective pressure, temperature, and porosity and decreased with increasing grain size. By comparing the observed strain rates and silica concentrations with theoretical rate laws, they conclude that the dominant mechanism for creep compaction was the removal of material from grain-to-grain contacts through intergranular pressure solution. The magnitude of the increase in silica concentrations observed with changes in effective confining pressure was too large to be accounted for by increases in elastic or plastic strain energy. This suggests that densification was driven by differences in normal stress between loaded grain boundaries and open pores. In addition, silica concentrations increased with decreasing grain size, providing an additional driving force for mass transfer that might promote healing and permeability reduction in fault gouges. The rapid densification rates observed by Dewers and Hajash and by Lockner and Evans reinforce the concept that porosity and permeability are dynamic parameters, which may evolve rapidly along faults at hydrothermal conditions.

In a series of experiments that are analogous to the Dewers and Hajash study, but at a much smaller scale, Hickman and Evans 
focused on identifying the mechanisms and kinetics of pressure solution at individual grain-to-grain contacts using in-situ observations in a heated microscope stage. In this series of experiments, Hickman and Evans measured the convergence between convex halite lenses and fused silica plates pressed together in brine at temperatures of 8 to $90^{\circ} \mathrm{C}$. They conclude that diffusion through a thin intergranular fluid film was the ratecontrolling process in these experiments and that the diffusivity of this film increased with decreasing normal stress. As this film has diffusivities many orders of magnitude greater than observed for solid-state grain boundaries and because no metastable islandchannel boundary structures were observed, they infer that this film was comprised of a tightly adsorbed (i.e., structured) water layer. Furthermore, convergence rates increased fivefold in an experiment conducted with a thin intergranular montmorillonite layer. Collectively, these experiments suggest that fine-grained, clay-rich fault gouges in the Earth should be particularly susceptible to both shear and compaction creep via pressure solution.

\section{Recommendations for Future Research}

Participants in the Conference on the Mechanical Effects of Fluids in Faulting identified a number of key topics for future research, each of which requires integration of knowledge from several fields and communication between specialists with different backgrounds. These research topics fall into three broad categories: geological observations of exhumed fault zones, laboratory experiments on natural and synthetic fault zone materials, and fault zone drilling combined with surface-based geophysical and geological investigations. The primary goal of these studies is to identify the processes and parameters that are most important in controlling fault zone rheology and that will therefore dominate the mechanics of faulting at different levels in the crust.

Studies of exhumed fault zones must be carefully designed to provide information on deformation mechanisms that operate at different crustal levels. These include fluid inclusion and mineral equilibria analyses that constrain the compositions, pressures, and temperatures of fluids both within and adjacent to fault zones. As noted by several conference participants, stress heterogeneities induced by fault slip and deformation can lead to considerable uncertainties in inferring past fluid pressures from observations of vein geometry in outcrop. Thus structural and fluid inclusion/mineralogical techniques must be combined to constrain fluid pressures during vein formation at different stages in the faulting cycle. Particular attention should also be paid to evidence for fluid communication, or lack thereof, between fault zones and country rock and evidence for or against cyclic dilatancy and gouge compaction within fault zones. Careful field mapping is needed to document the spatial scales over which structural, mineralogical, fluid-chemical, and hydraulic heterogeneity exists. More data on the existence, origin, dimensions, and temporal characteristics of abnormally pressured fluid compartments in and near fault zones are of paramount importance in this regard. In all of these investigations, it is important to recognize that a complex history of uplift and denudation may have severely altered, or even destroyed, evidence for deformation mechanisms operative during fault slip. Thus careful microstructural studies and determinations of past temperature and pressure conditions are required to assess the degree of annealing and other secondary alteration on samples collected from exhumed fault zones.

It is generally accepted that mylonites with well-ordered fabrics are predominantly the result of aseismic plastic shearing. In contrast, with the rare exception of localized melts generated by rapid seismic slip (i.e., the pseudotachylytes occasionally found in exhumed fault zones), no reliable way currently exists to distinguish the cataclastic products of seismic versus aseismic slip in fault zones. New laboratory friction experiments are needed at high rupture propagation and sliding velocities to constrain the mechanisms of dynamic rupture and, hopefully, to identify microstructures diagnostic of slip speed and stability. More laboratory experimentation is also required to document the importance of solution transport reactions and other fluid-rock interactions in controlling long-term fault strength, the stability of sliding, the evolution of fluid pressures along faults, and the timescales for interseismic strength recovery in the middle to lower crust. Crucial goals for experimentalists are carefully controlled studies to determine the rates at which various deformation and sealing/strengthening processes operate and how these rates depend upon mineralogy, fluid chemistry, grain size, and pore geometry. Finally, participants noted the importance of electrokinesis as a potential earthquake precursor, along with the need for experiments that investigate electromagnetic properties of rocks during fluid flow at elevated temperature and pressure.

Large-scale field experiments pertaining to the mechanical involvement of fluids in faulting that combine borehole observations with geophysical imaging along active faults are urgently needed. These experiments would provide critical tests of interpretations and hypotheses arising from laboratory rock mechanics experiments and geological observations on exhumed faults. Drilling provides the only direct means of measuring pore pressure, stress, permeability, and other important parameters within and near an active fault zone at depth. It is also the only way to collect fluid and rock samples from the fault zone and wall rocks at seismogenic depths and to monitor time-dependent changes in fluid pressure, fluid chemistry, deformation, temperature, and electromagnetic properties at depth during the earthquake cycle. However, fault zone drilling and downhole measurements must be accompanied by surface-based geological and geophysical observations, including active and passive seismic experiments and electrical surveys, to allow extrapolation of fluid pressure regimes and fault zone physical properties over a much larger volume than sampled by the borehole. For example, seismic tomography coupled with borehole monitoring may provide one of the best methods for real-time monitoring of both temporal and spatial variations in pore pressure during earthquakes and episodic fault slip.

Acknowledgments. We would like to thank Susan Larsen, Barbara Simpson, Muriel Jacobson, and Elaine Padovani for their help in making this workshop a success and Deborah Gray and the rest of the JGR and AGU editorial staffs for their hard work and perseverance in processing, editing, and producing this special section. This manuscript was improved through reviews by Mike Blanpied and Dave Hill. The Workshop on the Mechanical Involvement of Fluids in Faulting was sponsored by the National Earthquake Hazards Reduction Program of the U.S. Geological Survey.

\section{References}

Agricola, G., De Re Metallica 1556. Translated by H.C. and L.H. Hoover, Dover, Mineola N.Y., 638 pp., 1950.

Angevine, C. L., D. L. Turcotte, and M. D. Furnish, Pressure solution lithification as a mechanism for the stick-slip behavior of faults, Tectonics, $1,151-160,1982$.

Barr, T. D., and F. A. Dahlen, Constraints on friction and shear stress in the Taiwan fold-and-thrust belt from heat flow and geochronology, Geology, 18, 111-115, 1990 . 
Batzle, M.L., and G. Simmons, Geothermal systems: Rocks, fluids, fractures, in The Earth's Crust: Its Nature and Physical Properties, Geophys. Monogr. Ser., vol. 20, edited by J.C. Heacock, pp. 233-242, AGU, Washington, D.C., 1977.

Betins, B.A., and S.J. Dreiss, A simplified analysis of parameters controlling dewatering in accretionary prisms, Earth Planet. Sci. Lett., 109, 275-287, 1992.

Blanpied, M. L., D. A. Lockner, and J. D. Byerlee, Fault stability inferred from granite sliding experiments at hydrothermal conditions, Geophys. Res. Lett. 18, 609-612, 1991.

Blanpied, M. L., D. A. Lockner and J. D. Byerlee, An earthquake mechanism based on rapid sealing of faults, Nature, 358, 574-576, 1992.

Boullier, A.-M., and F. Robert, Paleoseismic events recorded in Archaean gold-quartz vein networks, Val d'Or, Albitibi, Quebec, Canada, $J$. Struct. Geol., 14, 161-179, 1992.

Brantley, S.L., B. Evans, S. Hickman, and D. Crerar, Healing of microcracks in quartz: Implications for fluid flow, Geology, 18, 136-139, 1990.

Brown, K.L., Gold deposition from geothermal discharges in New Zealand, Econ. Geol., 81, 979-983, 1986.

Bruhn, R.L., W.A. Yonkee, and W.T. Parry, Structural and fluid-chemical properties of seismogenic normal faults, Tectonophysics, 175, 139 $157,1990$.

Bruhn, R.L., W.T. Parry, W.A. Yonkee, and T. Thompson, Fracturing and hydrothermal alteration in normal fault zones, Pure Appl. Geophys., 142, 609-644, 1994

Brune, J. N., Rupture mechanism and interface separation in foam rubber models of earthquakes: A possible solution to the heat flow paradox and the paradox of large overthrusts, Tectonophysics, 218, 59-67, 1993.

Buckland, W., Geology and Mineralogy Considered With Reference to Natural Theology, William Pickering, London, 1836.

Byerlee, J.D., Friction, overpressure and fault normal compression, Geophys. Res. Lett., 17, 2109-2112, 1990

Byerlee, J., A model for episodic flow of high pressure water in fault zones before earthquakes, Geology, 21, 303-306, 1993.

Byrne, T., and D. Fisher, Evidence for a weak and overpressured décollement beneath sediment-dominated accretionary prisms, $J$. Geophys. Res., 98, 9081-9097, 1990.

Chester, F.M., Effects of temperature on friction: Constitutive equations and experiments with quartz gouge, J. Geophys. Res., 99, 7247-7261, 1994

Chester, F. M., and N.G. Higgs, Multimechanism friction constitutive model for ultrafine quartz gouge at hypocentral conditions, J. Geophys. Res., 97, 1859-1870, 1992

Chester, F. M., and J. M. Logan, Implications for mechanical properties of brittle faults from observations of the Punchbowl fault zone, California, Pure Appl. Geophys., 124, 79-106, 1986.

Chester, F.M., J.P. Evans, and R.L. Biegel, Internal structure and weakening mechanisms of the San Andreas fault, J. Geophys. Res., 98, 771-786, 1993.

Cox, S.F., M.A. Etheridge, and V.J. Wall, The role of fluids in syntectonic mass transport, and the localization of metamorphic vein-type ore deposits, Ore Geol. Rev., 2, 65-86, 1986.

Dahlen, F. A., Critical taper model of fold-and-thrust belts and accretionary wedges, Annu. Rev. Earth Planet. Sci., 18, 55-99, 1990.

Das, S., and C.H. Scholz, Theory of time-dependent rupture in the Earth, J. Geophys. Res., 86, 6039-6051, 1981.

Davis, D., J. Suppe, and F.A. Dahlen, The mechanics of fold and thrust belts and accretionary wedges, J. Geophys. Res., 88, 1153-1172, 1983.

Etheridge, M.A., V.J. Wall, S.F. Cox, and R.H. Vernon, High fluid pressure during regional metamorphism and deformation: implications for mass transport and deformation mechanisms, J. Geophys. Res., 89, 4344 4358, 1984.

Facca, G., and F. Tonani, The self-sealing geothermal field, Bull. Volcanol., 30, 271, 1967.

Fertl, W.H., G.V. Chilingarian, and H.H. Rieke, Abnormal Formation Pressures, Elsevier, New York, 1976.

Foumier, R.O., The transition from hydrostatic to greater than hydrostatic fluid pressure in presently active hydrothermal systems in crystalline rock, Geophys. Res. Lett., 18, 955-958, 1991.

Fredrich, J., and B. Evans, Strength recovery along simulated faults by solution transfer processes, Proc. U.S. Symp. Rock Mech., 33rd, 121130, 1992.

Fyfe, W.S., N.J. Price, and A.B. Thomson, Fluids in the Earth's Crust, Elsevier, New York, 1978.

Giggenbach, W.F., Y. Sano, and H. Wakita, Isotopic composition of helium, and $\mathrm{CO}_{2}$ and $\mathrm{CH}_{4}$ contents in gases produced along the New Zealand part of a convergent plate boundary, Geochim. Cosmochim. Acta, 57, 3427-3455, 1993.

Gratier, J.P., T. Chen, and R. Hellmann, Pressure solution as a mechanism for crack sealing around faults, in Proceedings USGS Red Book Conference on the Mechanical Involvement of Fluids in Faulting, edited by S. Hickman, R. Sibson, and R. Bruhn, U.S. Geol. Surv. Open File Rep., 94-228, 279-300, 1994.

Grindley, G.W., and P.R.L. Browne, Structural and hydrological factors controlling the permeability of some hot-water geothermal fields, in Proceedings of the 2nd United Nations Symposium on Development and Use of Geothermal Resources, vol. 1, pp. 377-386, U.S. Government Printing Office, Washington, D.C., 1976.

Guilbert, J.M., and C.F. Park, The Geology of Ore Deposits, W.H. Freeman, New York, 1985

Healy, J.H., W.W. Rubey, D.T. Griggs, and C.B. Raleigh, The Denver earthquakes, Science, 161, 1301-1310, 1968.

Hickman, S., Stress in the lithosphere and the strength of active faults, U.S. Nat. Rep. Int. Union Geod. Geophys. 1987.1990, Rev. Geophys., 29, 759-775, 1991.

Hickman, S., and B. Evans, Growth of grain contacts in halite by solution transfer: Implications for diagenesis, lithification, and strength recovery, in Fault Mechanics and Transport Properties of Rocks, edited by B. Evans and T.-F. Wong, pp. 253-280, Academic, San Diego, Calif., 1992.

Hickman, S., and S. Rojstaczer, In-situ study of physical mechanisms for permeability changes associated with the 1989 Loma Prieta earthquake, in Abstracts of the VIIth International Symposium on Observation of the Continental Crust Through Drilling, p. 119, Texas A\&M University, College Station, 1994

Hickman, S., R. Sibson, and R. Bruhn (Eds.), Proceedings USGS Red Book Conference on the Mechanical Involvement of Fluids in Faulting, U.S. Geol. Surv. Open File Rep., 94228, 615 pp., 1994.

Hubbert, M.K., and W.W. Rubey, Role of fluid pressure in mechanics of overthrust faulting, Geol. Soc. Am. Bull., 70, 115-205, 1959.

Hubbert, M.K., and D.G. Willis, Mechanics of hydraulic fracturing, Trans. Am. Inst. Min. Eng., 210, 115-205, 1957.

Hulin, C.D., Structural control of ore deposition, Econ. Geol. , 24, 15-49, 1925.

Hunt, J.M., Generation and migration of petroleum from abnormally pressured fluid compartments, AAPG Bull., 74, 1-12, 1990.

Irwin, W.P., and I. Barnes, Tectonic relations of carbon dioxide discharge and earthquakes, J. Geophys. Res., 85, 3115-3121, 1980.

Janecke, S.U., and J.P. Evans, Feldspar-influenced rock rheologies, Geology, 16, 1064-1067, 1988.

Kerrich, R., and I. Allison, Vein geometry and hydrostatics during Yellowknife mineralisation, Can. J. Earth Sci., 15, 1653-1660, 1978.

Kerrich, R., T.E. La Tour, and L. Willmore, Fluid participation in deep fault zones: Evidence from geological, geochemical, and ${ }^{18} \mathrm{O} /{ }^{16} \mathrm{O}$ relations, J. Geophys. Res., 89, 4331-4343, 1984.

Kirby, S. H., Tectonic stresses in the lithosphere: Constraints provided by the experimental deformation of rocks, $J$. Geophys. Res., 85, 6353$6363,1980$.

Knopf, A., The Mother Lode System of California, U.S. Geol. Surv. Prof. Pap., 157, 88 pp., 1929.

Lachenbruch, A.H., Frictional heating, fluid pressure, and the resistance to fault motion, J. Geophys. Res., 85, 6097-61 12, 1980.

Lachenbruch, A.H. and J.H. Sass, Heat flow and energetics of the San Andreas fault zone, J. Geophys. Res., 85, 6185-6223, 1980.

Logan, J. M., and K. A. Rauenzahn, Frictional dependence of gouge mixtures of quartz and montmorillonite on velocity, composition and fabric, Tectonophysics, 144, 87-108, 1987.

Magee, M.E., and M.D. Zoback, Evidence for a weak interplate thrust fault along the northern Japan subduction zone and implications for the mechanics of thrust faulting and fluid expulsion, Geology, 21, 809-812, 1993.

Marone, C., C. B. Raleigh, and C. H. Scholz, Frictional behavior and constitutive modeling of simulated fault gouge, J. Geophys. Res., 95, 7007-7025, 1990.

Mase, C.W., and L. Smith, Effects of frictional heating on the thermal hydrological, and mechanical response of a fault, J. Geophys. Res., 92, 6249-6272, 1987.

McKinstry, H.E., Mining Geology, Prentice-Hall, Englewood Cliffs, N.J., 1948.

Mead, W.J., The geologic role of dilatancy, J. Geol, 33, 685-698, 1925.

Moore, J.C., and P. Vrolijk, Fluids in accretionary prisms, Rev. Geophys. 30, 113-135, 1992. 
Moore, D.E., D. Lockner, and J. Byerlee, Reduction of permeability in granite at elevated temperatures, Science, 265, 1558-1561, 1994.

Morrow, C.A., L.Q. Shi and J.D. Byerlee, Strain hardening and strength of clay-rich fault gouges, J. Geophys. Res., 87, 6771-6780, 1982.

Morrow, C., B. Radney and J. Byerlee, Frictional strength and the effective pressure law of montmorillonite and illite clays, in Fault Mechanics and Transport Properties of Rocks, edited by B. Evans and T.-F. Wong, pp. 69-88, Academic, San Diego, Calif., 1992.

Muir-Wood, R., and G.C.P. King, Hydrological signatures associated with earthquake strain, J. Geophys. Res., 98, 22,035-22,068, 1993.

Newhouse, W.H., Openings due to movement along a curved or irregular fault plane, Econ. Geol, 35, 445-464, 1940.

Newhouse, W.H., Ore Deposits as Related to Structural Features, Princeton University Press, Princeton, N.J., 280 pp., 1942.

Nicholson, C., and R.L. Wesson, Earthquake hazard associated with deep well injection, U.S. Geol. Surv. Bull., 1951, 74 pp., 1990.

Nur, A., Dilatancy, pore fluids, and premonitory variations of $t_{s} / t_{p}$ travel times. Bull. Seismol. Soc. Am. 62, 1217-1222, 1972.

Nur, A., and J.R. Booker, Aftershocks caused by pore-fluid flow?, Science, $175,885-887,1972$.

Oxburgh, E.R., and R.K. O'Nions, Helium loss, tectonics, and the terrestrial heat budget, Science ,237, 1583-1588, 1987.

Parry, W.T. Fault fluid compositions from fluid inclusion observations, in Proceedings USGS Red Book Conference on the Mechanical Involvement of Fluids in Faulting, edited by S. Hickman, R. Sibson, and R. Bruhn, U.S. Geol. Surv. Open File Rep ., 94-228, 334-348, 1994.

Pine, R.J., and A.S. Batchelor, Downward migration of shearing in jointed rock during hydraulic injections, Int. J. Rock Mech. Min. Sci., 21, 229$263,1984$.

Pinkston, J., L. Stern, and S. Kirby, Hydrothermal reactions on artificial fault surfaces in dunite: Fibrous mineral growth, slickensides and temperature sensitivity of reaction weakening, Eos, Trans. AGU, 68, 405, 1987.

Platt, J.P., Dynamics of orogenic wedges and the uplift of high-pressure metamorphic rocks, Geol. Soc. Am. Bull., 97, 1037-1053, 1986.

Power, W. L., and T. E. Tullis, The relationship between slickenside surfaces in fine-grained quartz and the seismic cycle, J. Struct. Geol., $11,879-893,1989$.

Powley, D.E., Pressures and hydrogeology in petroleum basins, Earth Sci. Rev., 29, 215-226, 1990.

Raleigh, C.B., J.H. Healy, and J.D. Bredehoeft, An experiment in earthquake control at Rangely, Colorado, Science, 191, 1230-1237, 1976.

Ramsay, J.G., The crack-seal mechanism of rock deformation, Nature, 284, 135-139, 1980.

Rice, J. R., Fault stress states, pore pressure distributions, and the weakness of the San Andreas fault, in Fault Mechanics and Transport Properties of Rocks, edited by B. Evans and T.-F. Wong, pp. 475-503, Academic, San Diego, Calif., 1992.

Rice, J.R., and M.P. Cleary, Some basic stress diffusion solutions for fluid-saturated elastic porous media with compressible constiments, Rev. Geophys., 14, 227-241, 1976.

Robert, F., A.C. Brown, and A.J. Audet, Structural control of gold mineralization at the Sigma Mine, Val d'Or, Quebec, Can. Inst. Min Metall. Bull., 76, 72-80, 1983.

Rojstaczer, S., and S. Wolf, Permeability changes associated with large earthquakes: An example from Loma Prieta, California, Geology, 20, 211-214, 1992.

Rubie, D. C., Reaction-enhanced ductility: The role of solid-solid univariant reactions in deformation of the crust and mantle, Tectonophysics, 96, 331-352, 1983.

Rudnicki, J., Physical models of earthquake instability and precursory processes, Pure Appl. Geophys., 126, 531-524, 1988.

Rutter, E. H., and D. H. Mainprice, On the possibility of slow fault slip controlled by diffusive mass transfer processes, Gerlands Beitre. Geophys., 88, 154-62, 1979.

Scholz, C.H., L.R. Sykes, and Y.P. Aggarwal, Earthquake prediction: A physical basis, Science, 181, 803-810, 1973.

Shea, W.T., and A.K. Kronenberg, Strength and aniostropy of foliated rocks with varied mica contents, J. Struct. Geol., 15, 1097-1121, 1993.
Shipley, T.H., G.F. Moore, N.L. Bangs, J.C. Moore, and P.L. Stofta Seismically inferred dilatancy distribution, northem Barbados Ridge decollement: Implications for fluid migration and fault strength, Ged ogy, 22, 411-414, 1994.

Sibson, R.H., Interactions between temperature and pore-fluid prescere during earthquake faulting: A mechanism for partial or total stress relief, Nature Phys. Sci., 243, 66-68, 1973.

Sibson, R.H., Fluid flow accompanying faulting: Field evidence models, in Earthquake Prediction: An International Review, edited by D.W. Simpson and P.G. Richards, Am. Geophys, Union Maurice Eiving Series, 4, 593-603, 1981.

Sibson, R. H., Continental fault structure and the shallow earthquake source, J. Geol. Soc. London, 140, 741-767, 1983.

Sibson, R.H., Stopping of earthquake ruptures at dilational fault jogs. Nature, 316, 248-251, 1985.

Sibson, R.H., Rupture nucleation on unfavorably oriented faults, Bull. Seis. Soc. Am., 80, 1580-1604, 1990.

Sibson, R.H., Implications of fault valve behavior for rupture nucleation and recurrence, Tectonophysics, 211, 283-293, 1992.

Sibson, R.H., Crustal stress, faulting, and fluid flow, in Geofluids: Origin Migration, and Evolution of Fluids in Sedimentary Basins, edited by J. Parnell, Geol. Soc. Spec. Publ., London, 78, 69-84, 1994.

Sibson, R.H., F. Robert, and K.H. Poulson, High-angle reverse faults, fluid pressure cycling, and mesothermal gold-quartz deposits, Geology, $16,551-555,1988$.

Simpson, D.W., Triggered earthquakes, Annu. Rev. Earth Planet. Sci., 14, $21-42,1986$.

Sleep, N. H., and M.L. Blanpied, Creep, compaction, and the weak rheology of major faults, Nature, 359, 687-692, 1992.

Sleep, N. H., and M. L. Blanpied, Ductile creep and compaction; A mechanism for transiently increasing fluid pressure in mostly sealed fault zones, Pure Appl. Geophys., 143, 9-40, 1994.

Smith, L., C.B. Forster, and J.P. Evans, Interaction of fault zones, fluid flow and heat transfer on a basin scale, in Hydrogeology of Low Permeability Environments, edited by S.P. Newman and I. Neretnieks, Int. Assoc. Hydrol. Sci., Selected Papers, 2, 41-67, 1990.

Tada, R., R. Maliva, and R. Siever, A new mechanism for pressure solution in porous quartzose sandstone, Geochim. Cosmochim. Acte $51,2295-2301,1987$.

Tchalenko, J.S., Similarities between shear zones of different magnitudes, Geol. Soc. Am. Bull., 81, 1625-1640, 1970.

Terzaghi, K., Die theorie der hydrodynamischen spannungserscheinunget und ihr erdbautechnisches anwendungsgebeit, Proc. Int. Congr. Appl Mech. Delft, 288-294, 1924.

van den Beukel, J., and R. Wortel, Thermo-mechanical modeling of arctrench regions, Tectonophysics, 154, 177-193, 1988.

Von Oppel, Anleitung zur Markscheidekunst, Dresden, 1749.

Wakita, H., Y. Sano, and M. Mizoue, High ${ }^{3} \mathrm{He}$ emanation and seismic swarms observed in a nonvolcanic, forearc region, $J$. Geophys. Res., 92, 12,539-12,546, 1987.

Wu, F. T., Mineralogy and physical nature of clay gouge, Pure Appl. Geophys., 116, 655-689, 1978.

Zoback, M.D. and J.H. Healy, Friction, faulting, and "in situ" stresses, Ann. Geophys. , 2, 689-698, 1984

Zoback, M.D., and S.H. Hickman, In situ study of the physical mechanisms controlling induced seismicity at Monticello Reservoir, South Carolina, J. Geophys. Res., 87, 6959-6974, 1982.

Zoback, M.D., M.L. Zoback, V.S. Mount, J. Suppe, J.P. Eaton, J.H. Healy, D. Oppenheimer, P. Reasenberg, L. Jones, C.B. Raleigh, I.G. Wong, $O$. Scotti, and $C$. Wentworth, New evidence on the state of stress of the San Andreas fault system, Science, 238, 1105-1111, 1987.

R. Bruhn, Department of Geology and Geophysics, University of Utah, Salt Lake City, UT 84112. (e-mail: gg-rlb@ mines.utah.edu) S. Hickman, U.S. Geological Survey, 345 Middlefield Road, MS 977, Menlo Park, CA 94025. (e-mail: hickman @thepub.wr.usgs.gov)

R. Sibson, Department of Geology, University of Otago, P.O. Box 56, Dunedin, New Zealand. (e-mail: OUGEOLOGY@rivendell.otago.ac. nz)

(Received March 28, 1995; accepted March 31, 1995) 